\title{
Effect of Composition, Synthesis Protocol and Pellet Size of Cost Effective Adsorbents Doped with Flyash on Carbon Capture
}

\author{
B. Sreenivasulu, Ishan Vyas, Bansi M. Kamani, I. Sreedhar, and K. V. Raghavan
}

\begin{abstract}
CO}_{2}$ influe gas from anthropogenic emission is one of the major contributors for global warming among greenhouse gases (GHG). Alkaline metal oxide (CaO, MgO, etc) adsorbents got industrial importance due to its use at high temperature $\mathrm{CO}_{2}$ capture in coal gasification to separate hydrogen gas. In this paper, we discussed on the synthesis methods of mechanical mixing, freeze granulation and dispersion methods of adsorbents for $\mathrm{CO}_{2}$ capture. Operational issues of packed bed reactor used for $\mathrm{CC}$ using the alkaline earth metals doped flyash. Pore size and surface areas dependence of monolithic pellets on carbonation - calcination temperatures. CC variation with monolithic pellet size and carbonation temperatures. Breakthrough curves of adsorption for the adsorbents were discussed. Adsorbents of limestone doped with flyash were analyzed using various analytical tools and the findings were reported.
\end{abstract}

Index Terms-Alkaline metal oxides doped with flyash, carbon capture, operational experiences in packed bed reactor, synthesis protocol of monolithic adsorbents.

\section{INTRODUCTION}

Industrial implementation of carbon capture has become an urgent issue to mitigate global warming. Carbon capture is done with various technical options of absorption, adsorption, cryogenic separation and membrane separation [1], [2]. $\mathrm{CO}_{2}$ capture (CC) and separation from industrial process during coal gasification has got industrial importance due to its high temperature $\left(>400^{\circ} \mathrm{C}\right)$ capture from $\mathrm{H}_{2}+\mathrm{CO}_{2}$ gas mixture as shown in Fig. 1 [2].

Limestone doped on Flyash (FA) based porous adsorbents is an ecofriendly and possess resistance to moisture and other contaminants. The spent adsorbent could be used in cement manufacture [3]. CC by absorption suffers with regeneration energy penalty, environmental disposability of spent absorbent and less resistant to impurities in flue gas emissions for $\mathrm{CO}_{2}$ capture. Membrane separation also suffers with impurities in flue gas mixture, cost and disposability of spent material. Cryogenic separation needs energy penalty due to cryogenic temperatures used for $\mathrm{CO}_{2}$ separation from flue gas mixture. Limestone and dolomite are two minerals available at a very low cost and the spent material can be used in cement industry. But, this mineral has pore blocking nature is the

Manuscript received November 14, 2015; revised January 21, 2016.

B. Sreenivasulu, IshanVyas, Bansi M. Kamani, and I. Sreedhar are with the Department of Chemical Engineering, BITS Pilani Hyderabad Campus, Shameerpet, Hyderabad-78, India (e-mail: isreedhar2001@yahoo.co.in).

K. V. Raghavan is with Reaction Engineering Laboratory, Indian Institute of Chemical Technology, Tarnaka, Hyderabad, India. obstacle for complete carbonation. To avoid this issue we need to make this adsorbent as porous enough by using industrial waste inert support in the form of flyash. It also contains calcium and magnesium silicate to enhance further $\mathrm{CC}$ capacity of adsorbent. Since the $\mathrm{CO}_{2}$ adsorption depends on active sites availability on surface of adsorbent with basic sites $(\mathrm{MgO}, \mathrm{CaO})>$ amphoteric sites $\left(\mathrm{Al}_{2} \mathrm{O}_{3},\right)>$ acidic sites $\left(\mathrm{SiO}_{2}\right)$ [4], [5].

In this paper, limestone doped with $\mathrm{FA}$ is used for $\mathrm{CO}_{2}$ capture. Alkaline earth metal of $\mathrm{Mg}\left(\mathrm{NO}_{3}\right)_{2}+\mathrm{NaHCO}_{3}$ used for enhancement of alkalinity for faster carbonation reaction. Design of experiments based Taguchi method has been adopted for parameters based on composition of adsorbent, Synthesis method, binders and monolithic pellet size. Operational experience of experimental setup and measurements has been discussed. Instrument used monolithic pellets and equipment used for packed bed adsorption was reported. Effect of composition, synthesis methods, pellet size, crushing strength, surface area and binders are analyzed for CC. XRD (X-ray Diffraction), SEM (Scanning electron Microscope) and break through curves were discussed for further analysis and CC. Kinetic parameter estimation was calculated for the best performing adsorbent.

\section{EXPERIMENTAL METHOD}

Experimental schematic of the laboratory packed bed reactor setup for high temperature $\mathrm{CO}_{2}$ capture is shown in Fig. 2. The experimental setup is used for user defined composition of $\mathrm{CO}_{2}+\mathrm{N}_{2}$ gas mixture with mass flow controllers. Solid adsorbents of limestone doped flyash in the form of monolithic pellets could be placed in packed bed quartz reactor.

The quartz reactor has dimensions of $25 \mathrm{~mm}$ ID with $550 \mathrm{~mm}$ length and sustainable upto $1200^{\circ} \mathrm{C}$ at atmospheric pressure. Gas leakages at high temperatures could be avoided with graphite gaskets with quartz wool. The set value and the process value parameters difference must be below $50^{\circ} \mathrm{C}$ for temperature controllers to avoid any further damage to the electronic circuits inside the experimental setup.

The monolithic pellet sizes of $3 \mathrm{~mm}$ and $5 \mathrm{~mm}$ with an aspect ratio (ratio of thickness to diameter) must always be equal to 1 . Monolithic pellets made with pelletizer shown in Fig. 3. The pellets sizes are shown in Fig. 4 and Fig. 5. It is to have optimal strength to the pellet for minimal attrition loss during the cyclic process of carbonation and calcination in the pecked bed reactor. The monolithic pellets made of freeze granulation(FZ) method by dropping into liquid nitrogen. 
Mechanical mixing(MM) is through physical mixing of composition with binder. Dispersion method(DM) is done through the adsorbent composition and binder is mixed and then dispersed in polymer of poly ethylene glycol polymer (400m.wt). The design of experiment is explained in Table I. The best performing adsorbent is chosen based on $\mathrm{CC}$ at $650^{\circ} \mathrm{C}, 1 \mathrm{~atm}, 250 \mathrm{~cm}^{3} /$ minute flowrate, 60 minutes carbonation, $\left(33 \% \mathrm{CO}_{2}+67 \% \mathrm{~N}_{2}\right)$ gas mixture and with a sample size of
$10 \mathrm{gm}$ during the $1^{\text {st }}$ cycle $\mathrm{CO}_{2}$ capture. The best performing compositions from design of experiments were further optimized with parameters of temperature, flow rate, cycle time and flue gas concentrations. The sample composition $\left(\mathrm{CaO}: \mathrm{Mg}\left(\mathrm{NO}_{3}\right)_{2}: \mathrm{NaHCO}_{3}: \mathrm{FA}\right)$ weight $\%$ ratios were named as A1 for 40:10:20:30; A2 for 30:10:30:30; A3 for 40:20:10:30; A4 for 30:10:40:20.

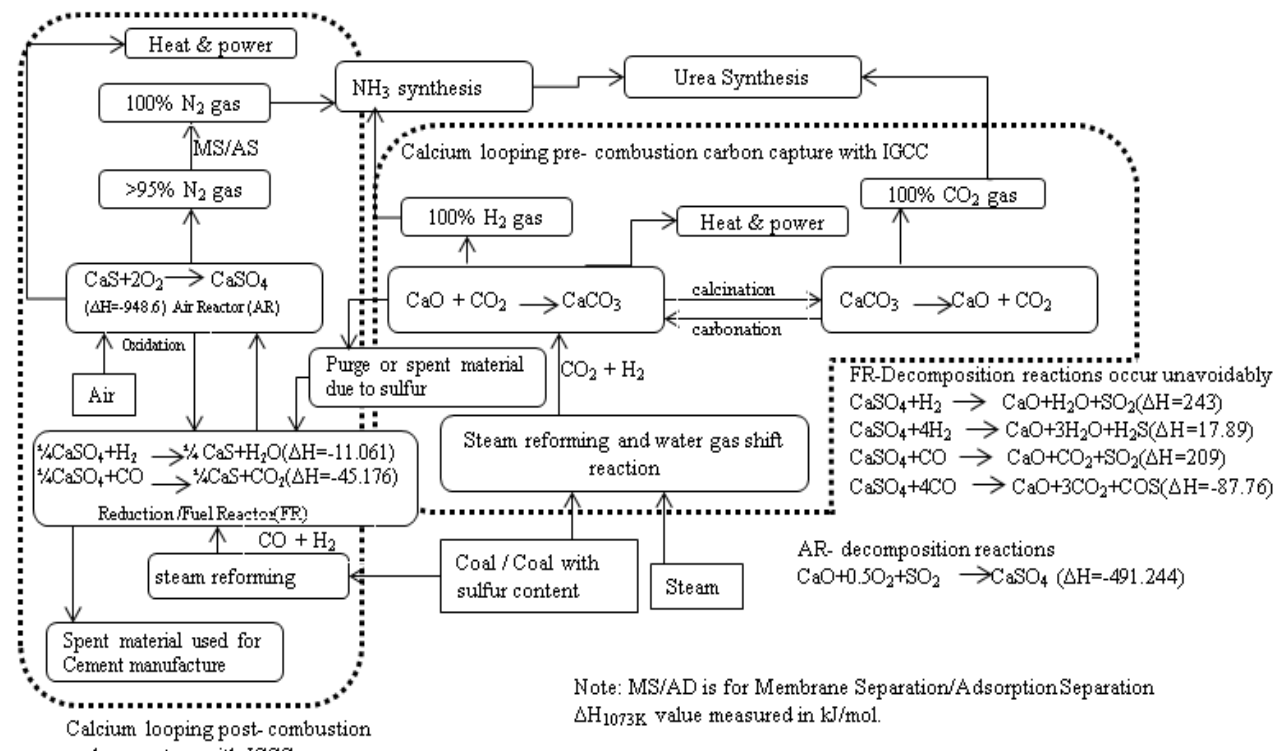

carbon capture with IGCC

Fig. 1. Limestone based adsorbent used in calcium looping for pre-combustion and post combustion CC.

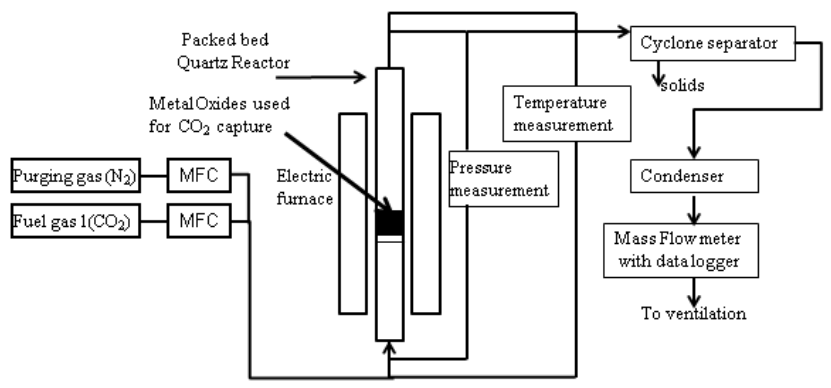

Fig. 2. Schematic of experimental setup used.

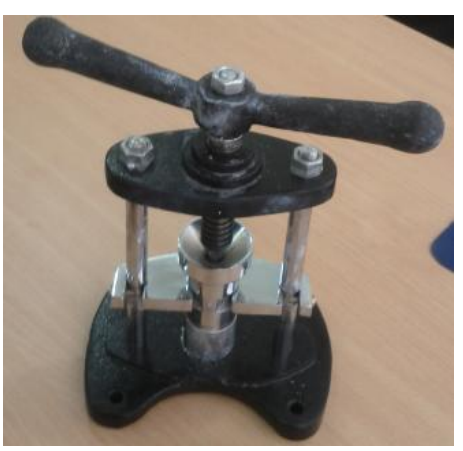

Fig. 3. Monolithic pelletizer.

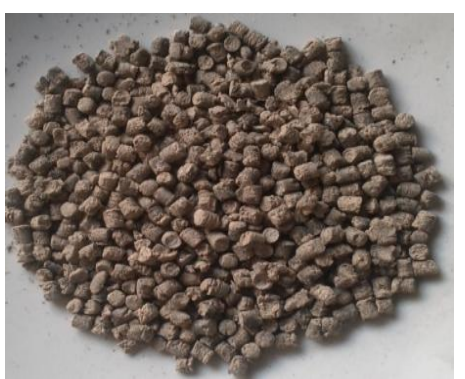

Fig. 4. $3 \mathrm{~mm} \times 3 \mathrm{~mm}$ monolithic pellet size.

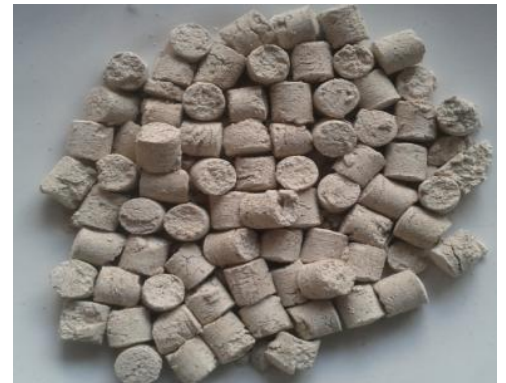

Fig. $5.5 \mathrm{~mm} \times 5 \mathrm{~mm}$ monolithic pellet size.

\section{RESUlTS AND DISCUSSION}

\section{A. Effect of Composition}

The fresh sample compositions of $\mathrm{CaO}: \mathrm{Mg}\left(\mathrm{NO}_{3}\right)_{2}: \mathrm{NaHCO}_{3}: \mathrm{FA}$ in combination of dispersion method and nitric acid binders were shown better $\mathrm{CO}_{2}$ captures than remaining combinations of binders and synthesis methods. Further improvement of cyclic carbonation and calcinations adsorbents were shown better capture capacities up to three cycles. Beyond third cycle the $\mathrm{CC}$ values remains constant and stable. The composition with $\mathrm{CaO}: \mathrm{Mg}\left(\mathrm{NO}_{3}\right)_{2}: \mathrm{NaHCO}_{3}: \mathrm{FA}(40: 20: 10: 30)$ shown better CC of $7.5 \mathrm{mmolCO}_{2} / \mathrm{g}$. As this is equivalent to the active material conversion capacity of $>50 \%$ and this gets increased to $9.5 \mathrm{mmolCO}_{2} / \mathrm{g}$ after the $3^{\text {rd }}$ cycle carbonation. But, the reported $\mathrm{MgO}+\mathrm{CaO}$ adsorbent gave a $\mathrm{CC}$ of 15.9 $\mathrm{mmolCO}_{2} / \mathrm{g}_{\mathrm{ads}}, 750^{\circ} \mathrm{C}, 100 \% \mathrm{CO}_{2}$ using TGA [6].

\section{B. Effect of Crushing Strength}

The adsorbent compositions of 
$\mathrm{CaO}: \mathrm{Mg}\left(\mathrm{NO}_{3}\right)_{2}: \mathrm{NaHCO}_{3}: \mathrm{FA}$ with weight ratios of 30:10:30:30 and 30:10:40:20 performed better strengths with a value of $15 \mathrm{~N} / \mathrm{cm}^{2}$ and $20 \mathrm{~N} / \mathrm{cm}^{2}$ respectively. The strength could be enhanced by sintering longer times of $>10 \mathrm{hr}$ at $1050^{\circ} \mathrm{C}$. But, Surface area and porosity may affect and results in lower CC capacity. The strength is retained up to $3^{\text {rd }}$ cycle for A2 and A4 sample. The sample A2 with $1 \mathrm{~mm}$ pellet size performed a CC capacity of 7.5, 7.51 and $7.6 \mathrm{mmolCO} / \mathrm{g}_{\text {ads }}$ in $1^{\text {st }}, 2^{\text {nd }}$ and $3^{\text {rd }}$ cycle respectively. It is observed that the CC capacities for A2 sample after $3^{\text {rd }}$ cycle for $1 \mathrm{~mm}, 3 \mathrm{~mm}$ and $5 \mathrm{~mm}$ pellet size are $7.6,6.82$ and $7.1 \mathrm{mmolCO}_{2} / \mathrm{g}_{\text {ads }}$ respectively. The CC capacities for sample A4 with $1 \mathrm{~mm}$, $3 \mathrm{~mm}$ and $5 \mathrm{~mm}$ pellet sizes are $6.1,6.2$ and 5.9 respectively. The maximum $\mathrm{CC}$ achieved after $3^{\text {rd }}$ cycle for selected samples of A2 (1mm size) and A4 (3mm size) were reported with nitric acid as binder using dispersion method of synthesis are 7.6 and $6.2 \mathrm{mmolCO}_{2} / \mathrm{g}_{\text {ads }}$ respectively. It was reported that the pellet form with $\mathrm{CC}$ of $0.52 \mathrm{mmolCO}_{2} / \mathrm{g}_{\text {ads }}$ and the optimal pellet size in the range of 2-5mm for effective $\mathrm{CO}_{2}$ adsorption [7]. $\mathrm{MgCO}_{3}$ starts decomposing from $300 \mathrm{oC}$ and re-carbonation also favors between $300^{\circ} \mathrm{C}$ to $900^{\circ} \mathrm{C}$ [8]. Calcium and magnesium silicates present in flyash decompose into alkaline carbonates while sintering the carbonated adsorbent of sample A2 and A4. Emitted $\mathrm{CO}_{2}$ from $\mathrm{CaCO}_{3}$ decomposition would accelerates the decomposition of $\mathrm{Ca}$ and $\mathrm{Mg}$ silicates into carbonates and then to alkaline oxides and silicon dioxides [9]-[11].

\begin{tabular}{|c|c|c|c|c|c|}
\hline Run No. & $\begin{array}{c}\text { Sample } \\
\text { name }\end{array}$ & $\begin{array}{l}\text { Synthesis } \\
\text { method }\end{array}$ & Binders & $\begin{array}{c}\text { Granule size } \\
(\mathrm{mm})\end{array}$ & $\begin{array}{c}\mathrm{CC} \\
(\mathrm{mmolCO} \\
\left.2 / \mathrm{g}_{\mathrm{ads}}\right) \\
\end{array}$ \\
\hline 1. & $\mathrm{~A} 1$ & $\mathrm{FZ}$ & Acetic Acid & 1 & 4.6 \\
\hline 2. & A1 & MM & Acetone & 3 & 3.2 \\
\hline 3. & A1 & DM & Nitric Acid & 5 & 7.2 \\
\hline 4. & A2 & $\mathrm{FZ}$ & Acetone & 3 & 3.8 \\
\hline 5. & A2 & MM & Acetic Acid & 5 & 3.5 \\
\hline 6. & A2 & DM & Nitric acid & 1 & 5.2 \\
\hline 7. & A3 & FZ & Nitric Acid & 5 & 5.2 \\
\hline 8. & A3 & MM & Acetone & 3 & 5.1 \\
\hline 9. & A3 & DM & Acetic Acid & 1 & 7.5 \\
\hline 10. & A4 & FZ & Nitric Acid & 1 & 5.4 \\
\hline 11. & A4 & DM & Acetone & 5 & 3.9 \\
\hline 12. & A4 & MM & Acetic Acid & 3 & 4.4 \\
\hline
\end{tabular}

\section{Effect of Binder}

Both acetic acid and acetone are weak acids than nitric acid, which is responsible for atomic level interactions with $\mathrm{CaO}$. During sintering process (at $1050^{\circ} \mathrm{C}$ ) these nitrates decomposes into active sites of metal oxides giving better $\mathrm{CC}$ at $650^{\circ} \mathrm{C}$.the carbonation at this high temperature is due to chemical adsorption made of covalent bonding of carbon dioxide with metal oxide compound [12]-[14]. Presence of calcium and magnesium in flyash making the adsorbent resistant to agglomeration.

\section{Effect of Synthesis Methods}

Mechanical methods and freeze granulation has lower level of atomic level mixing and atomic interaction in synthesis to have sufficient active sites for carbonation-calcination process. But, In dispersion method the adsorbent is dispersed polymer makes adsorbent get better mixing as well as atomic level interaction due to Nitric acid. This nitric acid is relatively stronger acidic in nature than that of acetone and acetic acid. Dispersion method of synthesis with nitric acid based synthesis of solid adsorbent gave higher $\mathrm{CO}_{2}$ capture due to higher alkalinity at the standard optimal operating conditions. It is reported that addition of alkaline metals and flyash enhances the carbonation and also alkaline silicates decomposition also contributes for enhancement along with synthesis methods for accelerated carbonation [12]-[15].

\section{E. Effect of Surface Area}

It has been observed that the surface area and $\mathrm{CO}_{2}$ capture increases proportionately to carbonation-calcination cycle number. After $3^{\text {rd }}$ cycle of carbonation (it is up to $3^{\text {rd }}$ cycle), the $\mathrm{CC}$ has nearly reached to constant value. Calcined adsorbent is me so porous and the carbonated adsorbent has higher surface area with decreased pore volume by becoming microporous carbonated. Effect of surface area on $\mathrm{CC}$ for sample A1 (1mm pellet size) increased from 7.5 to 8.1 $\mathrm{mmolCO}_{2} / \mathrm{g}_{\text {ads }}$ (S.A increased from 3.2 to $11.5 \mathrm{~m}^{2} / \mathrm{g}$ for $1^{\text {st }}$ to $3^{\text {rd }}$ cycle) of carbonation from $1^{\text {st }}$ cycle to $3^{\text {rd }}$ cycle. It is observed that the CC capacities for A1 sample after $3^{\text {rd }}$ cycle for $1 \mathrm{~mm}, 3 \mathrm{~mm}$ and $5 \mathrm{~mm}$ pellet size are $8.1,8.3$ and $8.2 \mathrm{mmolCO}_{2} / \mathrm{g}_{\text {ads }}$ respectively. The surface areas (S.A) for A1 sample after $3^{\text {rd }}$ cycle for $1 \mathrm{~mm}, 3 \mathrm{~mm}$ and $5 \mathrm{~mm}$ pellet size are $11.5,10.8$ and $10.4 \mathrm{~m}^{2} / \mathrm{g}_{\text {ads }}$ respectively. The CC capacities for sample A3 with $1 \mathrm{~mm}, 3 \mathrm{~mm}$ and $5 \mathrm{~mm}$ pellet sizes are 9.5 , 9.2 and 9 respectively. The surface areas (S.A) for A3 sample after $3^{\text {rd }}$ cycle for $1 \mathrm{~mm}, 3 \mathrm{~mm}$ and $5 \mathrm{~mm}$ pellet size are 11.3 , 11.1 and $11.5 \mathrm{~m}^{2} / \mathrm{g}_{\text {ads }}$ respectively. The surface areas of $\mathrm{A} 1$ and A3 sample (with pellet size of $1 \mathrm{~mm}$ ) increased from 3.2 $11.5 \mathrm{~m}^{2} / \mathrm{g}$ and $4.6-11.3 \mathrm{~m}^{2} / \mathrm{g}$ for $1^{\text {st }}$ to $3^{\text {rd }}$ cycle respectively. The S.A's increased from $1^{\text {st }}$ cycle to $3^{\text {rd }}$ cycle for the pellet sizes of 5mm samples of A1 and A3, are from 3.2-10.4 and $4.8-11.5 \mathrm{~m}^{2} / \mathrm{g}$ respectively. Similarly the CC capacities enhanced from 7.2-8.2 and 7.5-9 $\mathrm{mmolCO}_{2} /$ gads for samples with $5 \mathrm{~mm}$ pellet sizes of A1 and A3 respectively

\section{F. Analysis of XRD and SEM}

The XRD graphs revealed that there is significant increase in the peaks corresponding to the calcination of fresh sample to that of $3^{\text {rd }}$ cycle calcination after carbonation. The selected sample with $\mathrm{CaO}: \mathrm{Mg}\left(\mathrm{NO}_{3}\right)_{2}: \mathrm{NaHCO}_{3}: \mathrm{FA}(40: 20: 10: 30)$ gets converted into $\mathrm{CaO}$ and $\mathrm{MgO}$ after each cycle with enhanced crystallinity. Some of the silicates of calcium and magnesium present in flyash get carbonated and results in the $\mathrm{CO}_{2}$ capture increase by the adsorbent.

\section{G. Breakthrough Curves and Kinetics}

The carbonation and calcination cycles performed with 60 minutes interval each. The carbonation is performed for 60 minutes and the calcination is for 60 minutes to make sure the maximum conversion is achieved.

\section{CONCLUSIONS}

The monolithic pellets which are performing better CC were not having better crushing strength. The monolithic 
pellets compositions ( $\left.\mathrm{CaO}: \mathrm{Mg}\left(\mathrm{NO}_{3}\right)_{2}: \mathrm{NaHCO}_{3}: \mathrm{FA}\right)$ of 30:10:40:20 and 30:10:30:30 are showing better crushing strength in the range of $15-20 \mathrm{~N} / \mathrm{cm}^{2}$ or 0.15-0.2MPa.Addition of $\mathrm{NaHCO}_{3}$ with $30-40 \mathrm{wt} \%$ showing better pellet strength in $\mathrm{CaO}+\mathrm{MgO}+$ Flyash. Pellet based adsorbent makes this more suitable to multicycle capture capacities used in packed bed reactor with higher pressure drops. Pellet sizes of $<5 \mathrm{~mm}$ with sufficient strength comparable to cement based bricks to be improved. Suitable acid treatments of such as $\mathrm{HNO}_{3}$ research need to be done to improve surface area of high temperature carbon capture to be used pre-combustion carbon capture. Additional amount of $\mathrm{NaHCO}_{3}$ contributing enhanced pellet strength. Presence of $\mathrm{MgO}$ and $\mathrm{CaO}$ are not showing any agglomeration after the $3^{\text {rd }}$ cycle.

\section{ACKNOWLEDGEMENTS}

The authors would like to express their gratitude to the management of BITS-Pilani, for funding and other contributions towards the research work.

\section{REFERENCES}

[1] B. Sreenivasulu, D. V. Gayatri, I. Sreedhar, and K. V. Raghavan, "A journey into the process and engineering aspects of carbon capture technologies," Renew. Sustain. Energy Rev., 2015, vol. 41, pp. 1324-1350.

[2] B. Sreenivasulu, J. Deepika, I. Sreedhar, and K. V. Raghavan, "A critical review on the advances in the materials for carbon capture," presented at National Conference on Inter- \& Intra-Disciplinary Blend of Chemical Engineering, India, CHEMIX '15, March 28-29, 2015.

[3] B. Sreenivasulu, I. Sreedhar, P. Suresh, and K. V. Raghavan, "Development trends in porous adsorbents for carbon capture," Environmental Science and Technology, vol. 49, no. 21, pp. 12641-12661, 2015

[4] D. Bonenfant, L. Kharoune, S. Sauvé, R. Hausler, P. Niquette, M. Mimeault, and M. Kharoune, "Molecular analysis of carbon dioxide adsorption processes on steel slag oxides," Int. J. Greenh. Gas Control, vol. 3, pp. 20-28, 2009.

[5] J. M. Valverde, P. E. Sanchez-Jimenez, and L. A. Perez-Maqueda, "Ca-looping for postcombustion $\mathrm{CO}_{2}$ capture: A comparative analysis on the performances of dolomite and limestone," Appl. Energy, vol. 138, pp. 202-215, 2015.

[6] J. C. Mabry and K. Mondal, "Magnesian calcite sorbent for carbon dioxide capture," Environ. Technol., vol. 32, pp. 55-67, 2011.

[7] O. Aschenbrenner, P. McGuire, S. Alsamaq, J. Wang, S. Supasitmongkol, B. Al-Duri, P. Styring, and J. Wood, "Adsorption of carbon dioxide on hydrotalcite-like compounds of different compositions," Chem. Eng. Res. Des., vol. 89, pp. 1711-1721, 2011.

[8] S. Maitra, N. Chakrabarty, and J. Pramanik, "Decomposition kinetics of alkaline earth carbonates by integral approximation method," Cerâmica, vol. 54, pp. 268-272, 2008.

[9] S-Y Pan, " $\mathrm{CO}_{2}$ capture by accelerated carbonation of alkaline wastes: A review on Its principles and applications," Aerosol Air Qual Res, vol. 12, pp. 770-791, 2012.

[10] A. Kaithwas, M. Prasad, A. Kulshreshtha, and S. Verma. "Industrial wastes derived solid adsorbents for $\mathrm{CO}_{2}$ capture: A mini review," Chem Eng Res Des., vol. 90, 1632-1641, 2012.

[11] B. Reynolds, K. J. Reddy, and M. D. Argyle. "Field application of accelerated mineral carbonation," Minerals, vol. 4, pp. 191-207, 2014.

[12] V. Kumar, N. Labhsetwar, S. Meshram, and S. Rayalu, "Functionalized fly ash based alumino-silicates for capture of carbon dioxide," Energy \& Fuels, vol. 25, pp. 4854-4861, 2011.

[13] M. Ahmaruzzaman, "A review on the utilization of fly ash," Prog. Energy. Combust. Sci., vol. 36, pp. 327-363, 2010.

[14] C. Saha and S. Bhattacharya, "Chemical looping combustion of low-ash and high-ash low rank coals using different metal oxides - A thermogravimetric analyser study," Fuel., vol. 97, pp. 137-150, 2012.

[15] M. J. Ramírez-Moreno, I. C. Romero-Ibarra, J. Ortiz-Landeros, and H. Pfeiffer, "Alkaline and alkaline-earth ceramic oxides for $\mathrm{CO}_{2}$ capture, separation and subsequent catalytic chemical conversion," $\mathrm{CO}_{2}$ Sequestration Valorization, pp. 403-441, 2014.

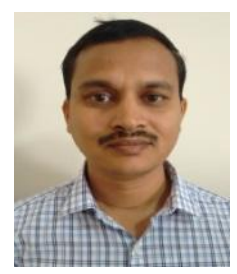

Bolisetty Sreenivasulu was born on June 1, 1973 at Proddatur, A.P State, India. He has done his under graduation degree, the B.Tech (1996) in chemical engineering from University College of Engineering. Sri Venkateswara University, Tirupati, AP State, India and the M.Tech (1999) in chemical engg. with major in process engineering from IT-BHU (now it is IIT-BHU), Varanasi, India; and the master of science in electrical engineering with major in molecular electronics and system design (2009) from ITN, Linkoping University, Sweden. He studied the certificate course on advanced design in VLSI (Jan-June, 2009), Linkoping University, Sweden. He was certified as OCP-DBA in oracle9i (2005) and oracle 11g from oracle corporation, USA (2011).

Currently he is studying as a Ph.D student at BITS-pilani, Hyderabad campus, India (2013 January onwards). He worked as research intern, focusing on "industrial process engineering screen printable conductive grid lines techniques in photovoltaic systems" at PARC, Xerox corporation Research division, Palo Alto, California, USA (April 2008 - October 2008). He worked as assistant professor of Chemical Engineering Department at BVRIT, Narsapur, Telangana State, India (July 2004 - Jan. 2006). He is a lecturer in Chemical Engg Department at ACE, Housr, TN State, India (June 1999 - June 2004). His research interests include chemical looping combustion, electronic porous materials and subject areas related to his qualification. Mr. Bolisetty is a life member of Indian Institute of Chemical Engineers (IIChE), India.

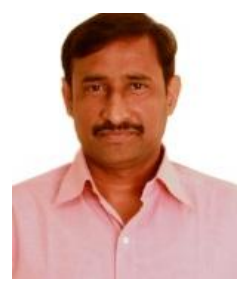

Inkollu Sreedhar was born on June 22, 1971 at Gannavaram, A.P State India. Hs has done his B.Tech in chemical engg from REC Warangal (1993), AP India; the M.Tech in chemical engg from IIT Delhi India with process engg and design as specialization (1994) and the PhD from BITS Pilani, Rajasthan India in chemical engg (2007).

He has more than 20 years of industrial experience, research and teaching. He has been working with BITS Pilani since 2001 as a lecturer in chemical eng till 2007, asst prof from 2008 till 2015 and assoc. prof. since Feb. 2015 till date. His research areas include reaction engg, heterogeneous catalysis, drag reduction, process development, process intensification, carbon capture. Published recently research and review articles in environmental science and technology, renewable and sustainable energy reviews, Korean journal chemical engg and published a book chapter in CRC press. Dr I. Sreedhar is a life member of IIChE, India.

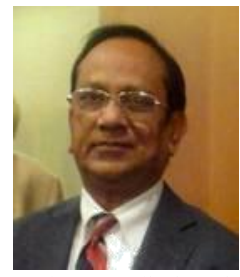

K. V. Raghava was born on October 1,1943 at Hyderabad, India. He has done his B.Tech in chemical engg from Osmania University, Hyderabad and the MS and the $\mathrm{PhD}$ in chemical engg from IIT Madras.

He joined in CSIR as a scientist in 1964, and held various critical positions of director of CLRI in 1994 director IICT, 1996 and chairman of DRDO in 2004 and INAE distinguished professor at IICT since 2008. His research interests are reaction engg, processs modeling and simulation, process development and design, chemical hazard analysis, carbon capture, process intensification etc. Published more than 120 research articles, filed 45 patents and edited 3books. He is the recipient of the Hindustan Lever Award of the Most Outstanding Chemical Engineer, NRDC Invention Promotion Award, Pilot Officer D V Ranga Reddy Gold Medal, J N Sinha Roy Memorial and ChemTech Foundation Awards, Nayudamma Gold Medal of AP Akademy of Sciences (2010) and Institution of Engineers Award of Outstanding Chemical Engineer (2010).

Dr. Raghavan is currently the member of Atomic Energy Regulatory Board and the Director of Heavy Water Board (Govt. of India), Mumbai, Godavari Biorefineries Ltd., (Mumbai) and Suven Life Sciences (Hyderabad). Dr. Raghavan is currently the chairman of the Research Council of CLRI, Chennai, and BITS, Pilani was represented on the Senate and Academic Councils of Anna University and School of Chemistry of Hyderabad University. He successfully coordinated the India's unique Biotechnology Incubation Centre establishedat Genome Valley, Hyderabad. He was the member of Scientific Advisory Committee of the Ministries of Petroleum and Natural Gas and Health of Government of India. He was the past President of Indian Institute of Chemical Engineers and A.P. Akademy of Sciences. Currently, he is the vice president (Academic and International Cooperation) of Indian National Academy of Engineering (INAE) and Federation of Asian Biotechnology Association (FABA). 